\title{
Antitumor Activities of Kushen: Literature Review
}

\author{
Mingyu Sun, ${ }^{1,2,3}$ Hongyan Cao, ${ }^{1}$ Lin Sun, ${ }^{4}$ Shu Dong, ${ }^{1}$ Yanqin Bian, ${ }^{1}$ Jun Han, ${ }^{5}$ Lijun Zhang, \\ Shuang Ren, ${ }^{1}$ Yiyang Hu, ${ }^{1,2,3}$ Chenghai Liu, ${ }^{1,2,3}$ Lieming Xu, ${ }^{1,2,3}$ and Ping Liu ${ }^{1,2,3}$
}

\author{
${ }^{1}$ Key Laboratory of Liver and Kidney Diseases, Institute of Liver Diseases, Shuguang Hospital, Shanghai University of \\ Traditional Chinese Medicine, 528 Zhangheng Road, Pudong New Area, Shanghai 201203, China \\ ${ }^{2}$ Shanghai University of Traditional Chinese Medicine, 528 Zhangheng Road, Pudong New Area, Shanghai 201203, China \\ ${ }^{3}$ E-institute of Shanghai Municipal Education Commission, Shanghai 201203, China \\ ${ }^{4}$ Liaoning University of Traditional Chinese Medicine, Shenyang 100032, China \\ ${ }^{5}$ School of Pharmacy, Second Military Medical University, Shanghai 201203, China
}

Correspondence should be addressed to Mingyu Sun, mysun248@hotmail.com and Ping Liu, liuliver@vip.sina.com

Received 4 January 2012; Revised 30 May 2012; Accepted 7 June 2012

Academic Editor: Francesca Borrelli

Copyright (๑) 2012 Mingyu Sun et al. This is an open access article distributed under the Creative Commons Attribution License, which permits unrestricted use, distribution, and reproduction in any medium, provided the original work is properly cited.

To discover and develop novel natural compounds with therapeutic selectivity or that can preferentially kill cancer cells without significant toxicity to normal cells is an important area in cancer chemotherapy. Kushen, the dried roots of Sophora flavescens Aiton, has a long history of use in traditional Chinese medicine to treat inflammatory diseases and cancer. Kushen alkaloids (KSAs) and kushen flavonoids (KS-Fs) are well-characterized components in kushen. KS-As containing oxymatrine, matrine, and total alkaloids have been developed in China as anticancer drugs. More potent antitumor activities were identified in KS-Fs than in KS-As in vitro and in vivo. KS-Fs may be developed as novel antitumor agents.

\section{Introduction}

To discover and develop novel natural compounds with therapeutic selectivity or that can preferentially kill cancer cells without significant toxicity to normal cells is an important area in cancer chemotherapy. Because of their wide range of biological activities and low toxicity in animal models, some natural products have been used as alternative treatments for cancers. Many anticancer drugs are derived from naturally occurring compounds. Vinca alkaloids (e.g., vinblastine, vincristine) and taxol are examples of such compounds.

The traditional Chinese medicine kushen is the dried roots of Sophora flavescens Aiton (Leguminosae). It was first described in the Chinese book Shen Nong Ben Cao Jing in 200 A.D. as a treatment for solid tumors, inflammation, and other diseases [1]. The traditional use of kushen includes the decoction or powder of dried plant roots. It is commonly used for the treatment of viral hepatitis, cancer, enteritis, viral myocarditis, arrhythmia, and skin diseases (e.g., colpitis, psoriasis, eczema) [2].
The known chemical components of kushen include alkaloids (3.3\%), flavonoids (1.5\%), alkylxanthones, quinones, triterpene glycosides, fatty acids, and essential oils [2, 3]. Kushen alkaloids (KS-As) and kushen flavonoids (KS-Fs) are well-characterized components in kushen. KS-As have been developed as anticancer drugs in China. More potent antitumor activities have been identified in KS-Fs than in KS-As [4].

\section{KS-As}

KS-As have been well studied and are considered to be the major active components of kushen as demonstrated in experimental animal models [5-8] and clinical studies [914]. The bioactivities of kushen (including antitumor, antiviral and anti-inflammatory activities) have been shown in the KS-As fraction [6].

KS-As containing oxymatrine, matrine (Figure 1), and total alkaloids were approved for the treatment of cancer patients by the Chinese State Food and Drug Administration (SFDA) in 1992. Multiple KS-As products have been used 


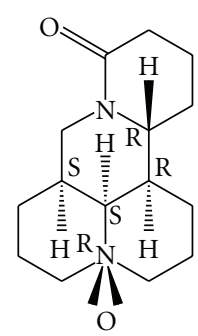

Oxymatrine $\mathrm{C}_{15} \mathrm{H}_{24} \mathrm{~N}_{2} \mathrm{O}_{2}$

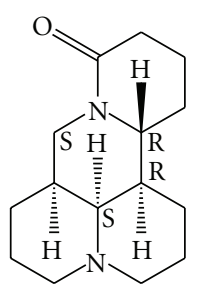

Matrine $\mathrm{C}_{15} \mathrm{H}_{24} \mathrm{~N}_{2} \mathrm{O}$<smiles>[R]C(C=C(C)C)(C=C(C)C)CCc1c(O)cc(OC)c2c1OCC(c1ccc(O)cc1OC)CC2=O</smiles>

$2^{\prime}$-methoxykurarinone $\mathrm{C}_{27} \mathrm{H}_{32} \mathrm{O}_{6}$<smiles>C=C(C)[C@H](CC=C(C)C)Cc1c(O)cc(O)c2c1O[C@H](c1ccc(O)cc1O)CC2=O</smiles>

Sophoraflavanone $\mathrm{G}_{25} \mathrm{H}_{28} \mathrm{O}_{6}$<smiles>C=C(C)C(CCC(C)(C)O)Cc1c(O)cc(O)c2c1OC(c1ccc(O)cc1O)CC2=O</smiles>

Norkurarinol $\mathrm{C}_{25} \mathrm{H}_{30} \mathrm{O}_{7}$<smiles>OC[C@H]1O[C@@H](Oc2ccc3c(c2)OC[C@H]2c4cc5c(cc4O[C@H]32)OCO5)[C@H](O)[C@@H](O)[C@@H]1O</smiles>

Trifolirhizin $\mathrm{C}_{22} \mathrm{H}_{22} \mathrm{O}_{10}$<smiles>C=C(C)C(CC=C(C)C)Cc1c(O)cc(OC)c(C(=O)/C=C/c2ccc(O)cc2O)c1O</smiles>

Kuraridin $\mathrm{C}_{26} \mathrm{H}_{30} \mathrm{O}_{6}$<smiles>C=C(C)CC[C](Cc1c(O)cc(OC)c2c1O[C@@H](c1ccc(O)cc1O)CC2=O)C(=C)C</smiles>

Kurarinone $\mathrm{C}_{26} \mathrm{H}_{30} \mathrm{O}_{6}$<smiles>C=C(C)C(C/C=C\C)Cc1c(O)cc2c(c1O)C(=O)CC(c1ccc(O)cc1O)O2</smiles>

Kushenol F $\mathrm{C}_{25} \mathrm{H}_{28} \mathrm{O}_{6}$

FIgURE 1: The molecular structure of antitumer compounds derived from Sophora flavescens. 
widely in China for the treatment of cancers and hepatitis. The SFDA-approved KS drugs for oncology are all KS-As used as single agents or in combination with chemotherapy or radiotherapy. Few studies focused on the efficacy of KS-As in animal models and clinical trials before 1992, when KS-As was first approved.

Several clinical studies reported that KS-As were efficacious in the treatment of various types of solid tumors (including lung, liver, and gastrointestinal tract). The treatment responses were comparable to, or better than, that of chemotherapy drug-treated patients (Table 1) [11, 14-32]. KS-As demonstrates a good safety profile in cancer patients, such as reduced toxicity in the bone marrow when used in combination with chemotherapy agents [33]. Long-term survival data for KS-As-treated cancer patients remains to be demonstrated with well-controlled clinical studies and large patient cohorts.

\section{Matrine and Oxymatrine}

Matrine and oxymatrine (Figure 1) are the two major alkaloid components found in the roots of Sophora species. They are obtained primarily from Sophora japonica (kushen), Sophora subprostrata (shandougen), and from the overground portion of Sophora alopecuroides. The matrines were first isolated and identified in 1958; they are unique tetracyclo-quinolizindine alkaloids found only in Sophora species thus far [52-56].

In vitro studies have demonstrated that matrine and oxymatrine weakly inhibit the growth of various human tumor cell lines with a half-maximal inhibitory concentration $\left(\mathrm{IC}_{50}\right)$ of $1.0-4.0 \mathrm{mg} / \mathrm{mL}$ [57-61].

In vivo studies have shown that KS-As, oxymatrine, and matrine inhibit the growth of murine tumors, including $\mathrm{H} 22$, hepatoma, S180, sarcoma, and MA737 breast cancer cells $[58,60,62,63]$. In a human xenograft tumor model using the SGC-7901 cell line, matrine enhanced the inhibition of 5-fluorouracil in the tumor [33].

Matrine can also inhibit the invasiveness and metastasis of the human malignant melanoma cell line A375 and cervical cancer HeLa cells, as well as induce differentiation of leukemia K-562 cells [64-66]. In addition, matrine-induced autophagy in rat C6 glioma cells has been observed by electron microscopy [67].

The antitumor response of KS-As was further demonstrated in several clinical studies in various types of cancers, including stomach, esophagus, liver, colon, lung, cervix, ovary, and breast cancers, as a single agent [9-14] or in combination with chemotherapy [15-18] or radiotherapy [68]. It has been reported that matrine exerts its antitumor effects by inhibiting the proliferation and inducing the apoptosis of gastric and cervical cancer cells as well as leukemic and glioma cells [34, 67-70].

Several in vitro and in vivo studies have tried to elucidate the mechanism of action of matrine. Matrine promotes apoptosis in leukemic [35], breast cancer [36], nonsmall-cell lung cancer [37], hepatocarcinoma, and gastric cancer cells [38] by a mitochondrial-mediated pathway [39]. Beclin 1 is involved in matrine-induced autophagy, and the proapoptotic mechanism of matrine may be related to its upregulation of Bax expression [39]. Recent evidence indicates that matrine also has appreciable effects in modulating the immune response by reducing the invasion and metastasis of HCC cells $[40,41,71]$.

Tissue homeostasis requires a balance between the division, differentiation and death of cells. A tumor is a type of "cell cycle disorder" that has the abnormal interface of division, differentiation and death [42]. As a "biological modifier" of cells, matrine can reverse the abnormal biologic behavior of tumor cells and recover the balance between the division, differentiation, and death of cells.

Matrine can also inhibit the invasiveness and metastasis of the human malignant melanoma cell line A375 [43]. Some studies reported that matrine reduced the adhesion and migration of HeLa cells [72]. The mechanisms of action of matrine against cancer cell proliferation and invasion are associated with epidermal growth factorvascular endothelial growth factor vascular endothelial growth factor receptor 1 Akt-nuclear factor-kappa B (EGF/VEGF-VEGFR1-AktNF- $\kappa$ B) signaling [36] (Table 2).

Matrine displays synergistic effects with the anticancer agents celecoxib (cyclooxygenase-2 inhibitor), trichostatin A (histone deacetylase inhibitor) and rosiglitazone against the tumor proliferation and VEGF secretion. Matrine may have broad therapeutic and/or adjuvant therapeutic applications in the treatment of human nonsmall-cell lung cancer, breast cancer, and hepatoma [36, 37] (Table 2).

Some studies have also reported upon the anticancer activity of oxymatrine in human gastric cancer cells, pancreatic cancer, and human breast cancer cells [73-75]. Oxymatrine can induce the apoptosis death of human pancreatic cancer cells, which might be attributed to the regulation of Bcl-2 and IAP families, release of mitochondrial cytochrome C, and activation of caspase-3 [74] (Table 2).

Compound kushen injection (CKI), commonly known as Yanshu injection, is extracted from two herbs, kushen (Radix Sophorae Flavescentis) and Baituling (Rhizoma Smilacis Glabrae), with the primary components being oxymatrine and matrine [75]. CKI has been used extensively alone or in combination with chemotherapy or radiotherapy for many years in China. Clinical studies have shown that CKI attenuates the side effects of chemotherapy and radiotherapy by improving the quality of life and regulating the immune function of cancer patients, as well as synergizing the therapeutic effects of chemotherapy and radiotherapy (Table 1) $[15-32,76]$. It has been demonstrated that CKI suppresses the growth of tumor cells by inducing apoptosis and inhibiting the migration, invasion, and adhesion, of such cells [77].

Cancer stem cells (CSCs) play an important part in the initiation, relapse and metastasis of cancer. A specific agent has not been found to target CSCs because they are resistant to most conventional therapies and proliferate indefinitely. In one study, CKI suppressed the size of the side population (SP; $~ 90 \%)$ and downregulated the main genes of the Wnt signaling pathway in MCF-7 SP cells. CKI suppressed tumor growth by downregulating the $\mathrm{Wnt} / \mathrm{b}$-catenin pathway, 


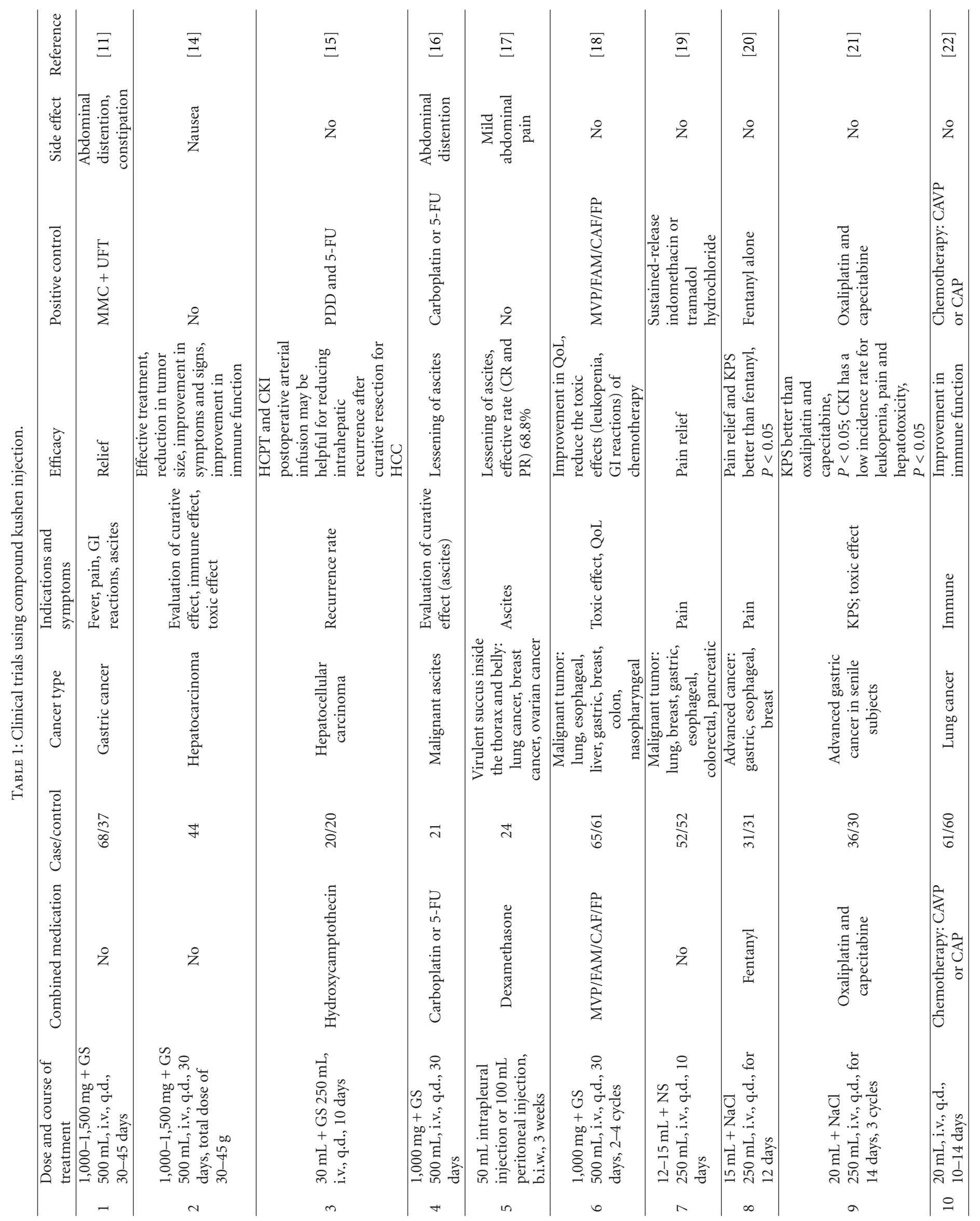




\begin{tabular}{|c|c|c|c|c|c|c|c|}
\hline 节 & $\sqrt[\widetilde{d}]{ }$ & $\underset{\Xi}{\Xi}$ & $\stackrel{\sqrt[\pi]{\Perp}}{ }$ & ¿ & $\widehat{\beth}$ & 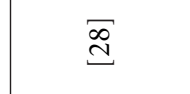 & $\overline{\mathrm{I}}$ \\
\hline 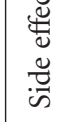 & $\stackrel{\circ}{z}$ & $\stackrel{\circ}{z}$ & $\stackrel{\circ}{z}$ & $\stackrel{2}{z}$ & ż & z & $\stackrel{\circ}{z}$ \\
\hline 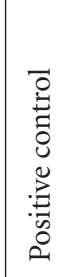 & 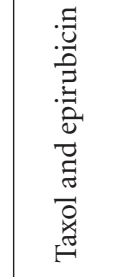 & 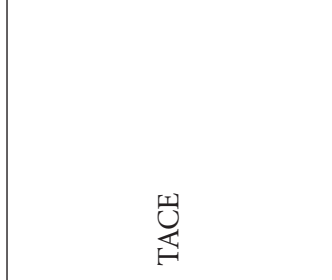 & 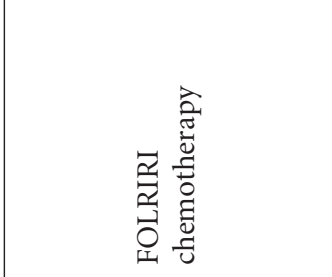 & 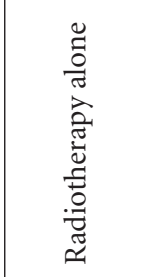 & 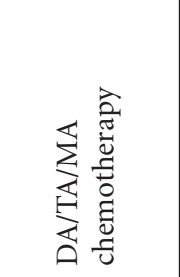 & 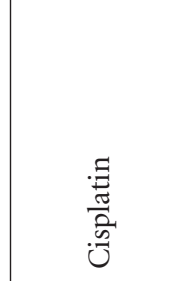 & 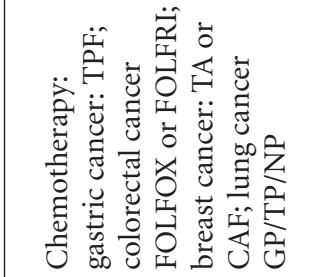 \\
\hline 苞 & 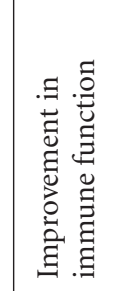 & 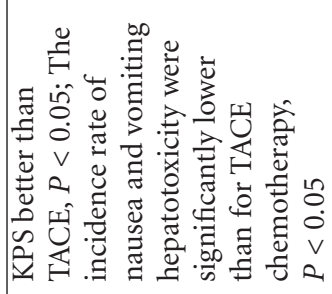 & 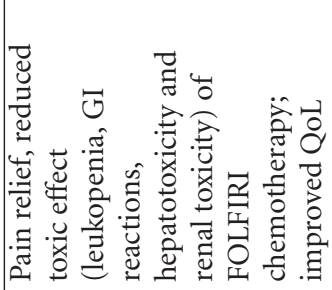 & 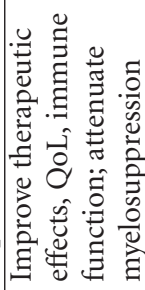 & 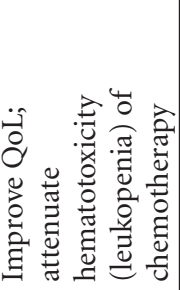 & 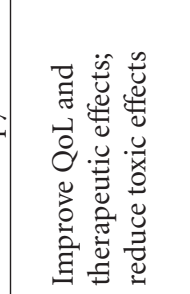 & 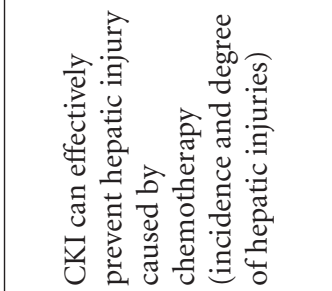 \\
\hline 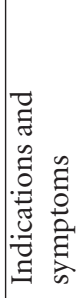 & $\begin{array}{l}\text { 节 } \\
\text { 亶 }\end{array}$ & 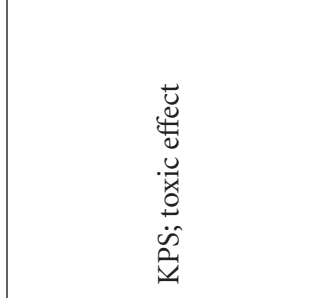 & 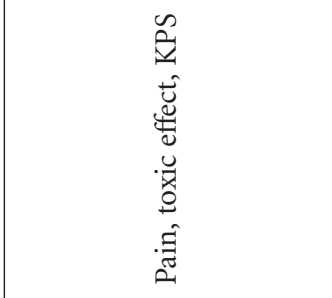 & 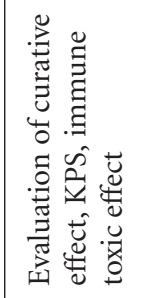 & 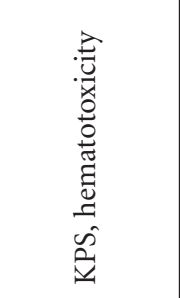 & 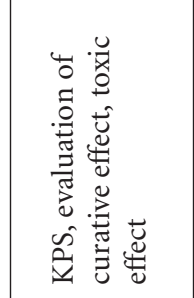 & 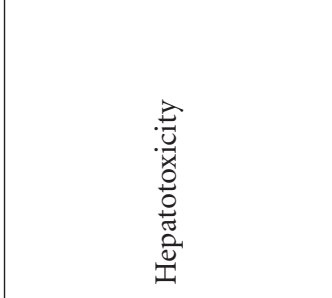 \\
\hline 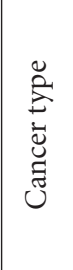 & 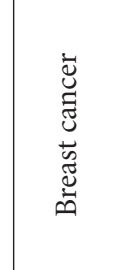 & 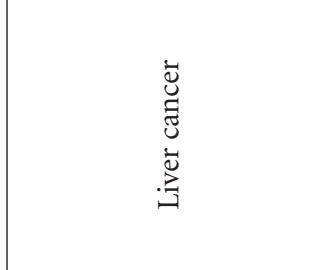 & 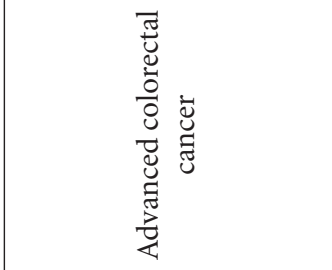 & 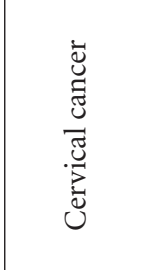 & $\sum_{<}$ & 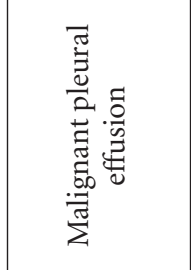 & 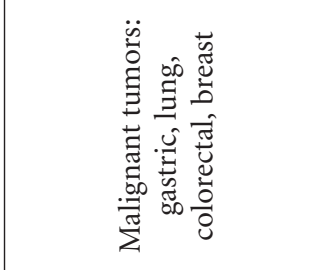 \\
\hline 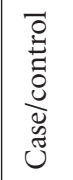 & $\stackrel{m}{m}$ & 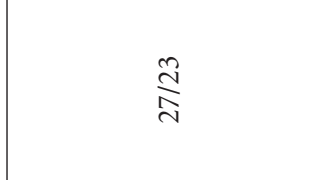 & 号 & $\stackrel{m}{m}$ & 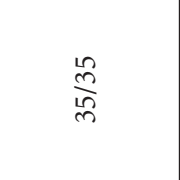 & $\underset{\text { लn }}{\stackrel{m}{\pi}}$ & $\underset{\infty}{\infty}$ \\
\hline 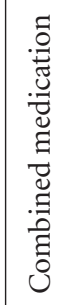 & 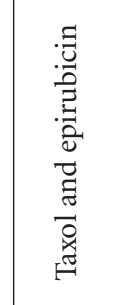 & 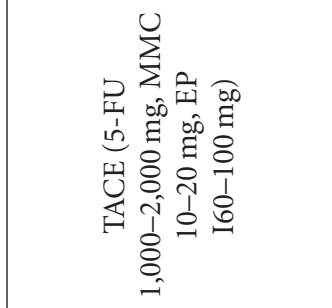 & 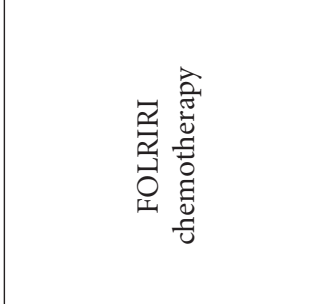 & 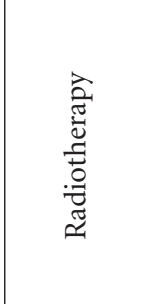 & 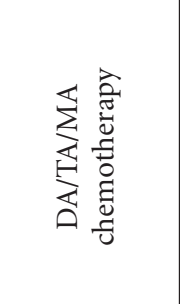 & 之े & 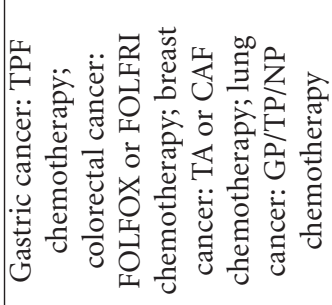 \\
\hline 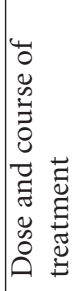 & 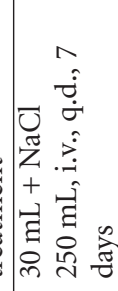 & 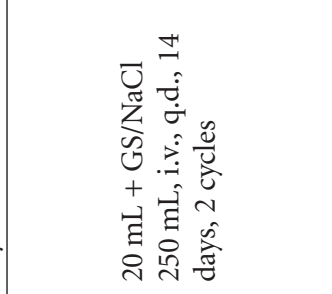 & 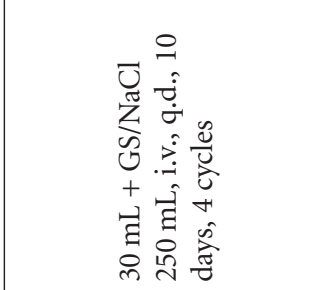 & 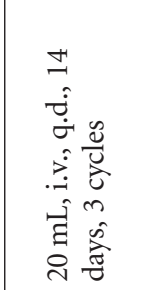 & 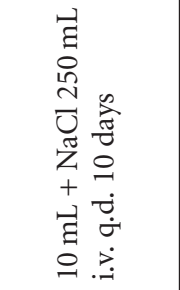 & 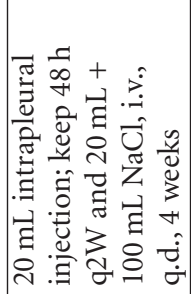 & 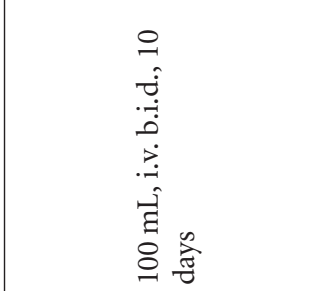 \\
\hline & $=$ & $\simeq$ & 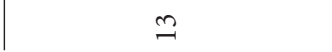 & $\exists$ & $\stackrel{n}{n}$ & $\stackrel{0}{\circ}$ & $\approx$ \\
\hline
\end{tabular}




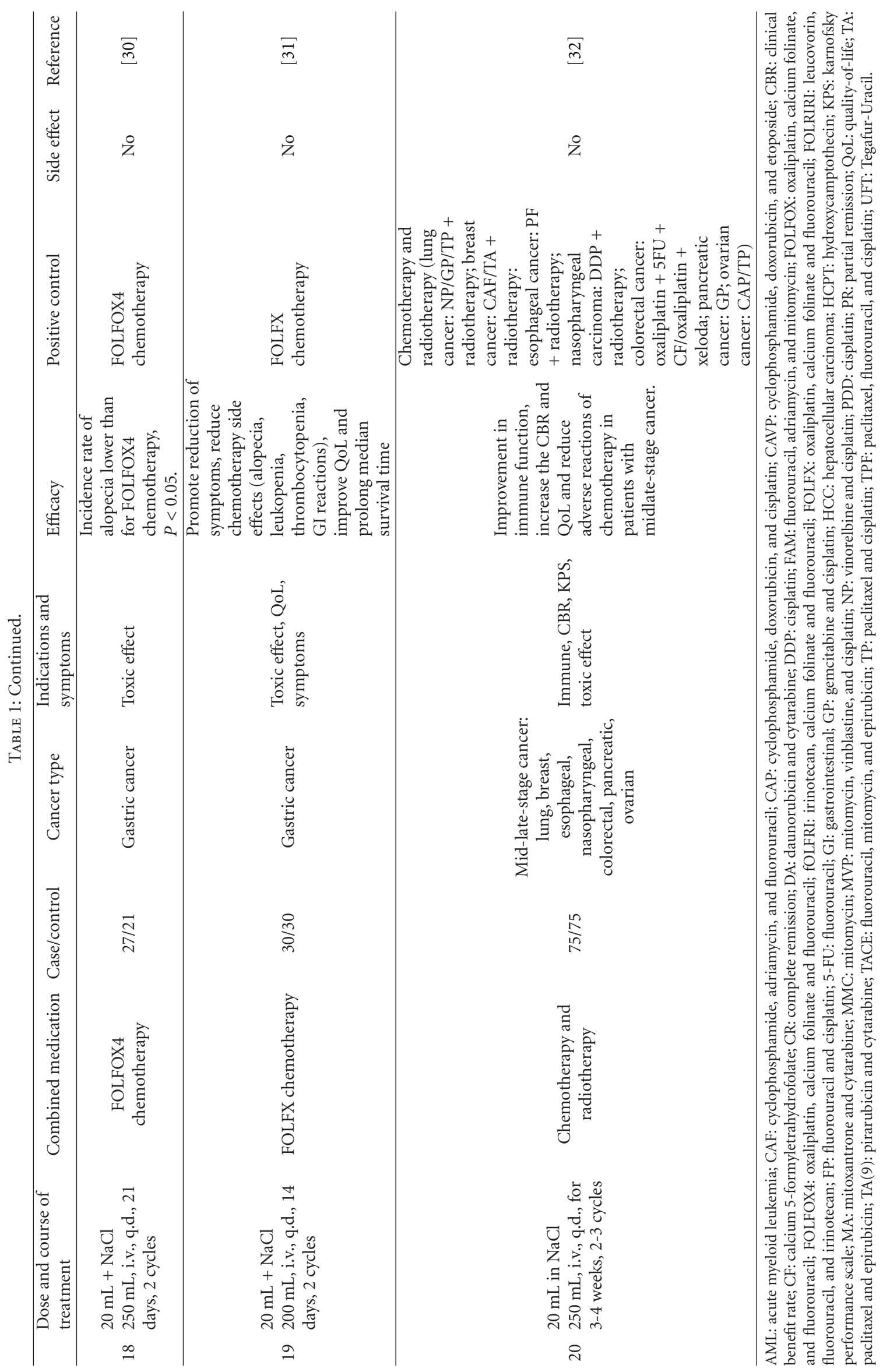


TABLE 2: Mechanism of action of the chemotherapy of kushen compounds.

\begin{tabular}{|c|c|c|}
\hline Compound & Mechanisms of action & Reference \\
\hline \multirow{3}{*}{ Matrine } & Promotes apoptosis via mitochondria & [34-38] \\
\hline & Modulates the immune response & [39-41] \\
\hline & Inhibits EGF/VEGF-VEGFR1-Akt—NF- $\kappa$ B signaling & {$[35,42,43]$} \\
\hline Compound kushen injection & Inhibits cancer stem cells & {$[44]$} \\
\hline $\begin{array}{l}\text { Kuraridin, sophoraflavanone G, kurarinone, } \\
\text { kushenol F, and norkurarinol }\end{array}$ & Strong tyrosine kinase inhibitory activity & {$[45-49]$} \\
\hline Kurarinone & Inhibits TNF $\alpha$ l-induced NF- $\kappa \mathrm{B}$ activation and enhances apoptosis & {$[45,50,51]$} \\
\hline Kurarinone and kuraridin & $\begin{array}{l}\text { Attenuate NF- } \kappa \mathrm{B} \text { activation by inhibition of } \mathrm{I} \kappa \mathrm{B} \alpha \text { proteolysis and p } 65 \\
\text { nuclear translocation as well as phosphorylation of ERK1/2, JNK, and p } 38 \\
\text { MAP kinases }\end{array}$ & {$[45,51]$} \\
\hline
\end{tabular}

whereas cisplatin activated the Wnt/b-catenin pathway and could spare SP cells. These data suggested that CKI may serve as a novel drug targeting CSCs, but further studies are recommended [44].

\section{KS-Fs}

The antitumor effects of some flavonoid compounds (Figure 1) have been demonstrated in vitro and in vivo [78-82]. Surprisingly, the antitumor activities of KS-Fs were more potent than those of KS-As, which have been considered to be the major active components in the plant [83]. KS-Fs such as kurarinone, $2^{\prime}$-methoxykurarinone, and sophoraflavanone $\mathrm{G}$ (lavandulyl flavanones isolated from $S$. flavescens) (Figure 1) can inhibit cell proliferation in A549, NCI-H460 (nonsmall-cell lung), SK-OV-3 (ovary), SK-MEL2 (skin), XF498 (central nerve system), HCT-15 (colon) HL60 (myeloid leukemia) and SPC-A-1 (lung) cells with $\mathrm{IC}_{50}$ values between $2 \mu \mathrm{g} / \mathrm{mL}$ and $36 \mu \mathrm{g} / \mathrm{mL}[80,82,83]$.

Antitumor efficacies were confirmed in mice models of H22, S180 and Lewis lung tumors as well as nude mice models of human H460 and Eca-109 xenografted tumors $[45,83]$. Moreover, KS-Fs and kurarinone enhanced the antitumor activities of Taxol in vitro and in vivo $[83,84]$. The oral or intravenous maximum tolerated dose of KS-Fs was $>2.8 \mathrm{~g} / \mathrm{kg}$ or $750 \mathrm{mg} / \mathrm{kg}$, respectively, appreciably more than the oral median lethal dose of KS-As $(\leq 1.18 \mathrm{~g} / \mathrm{kg})$. Adverse reactions were not observed. In addition, peripheral blood cell counts were not significantly affected in normal mice treated with KS-Fs at $200 \mathrm{mg} / \mathrm{kg} /$ day for 2 weeks [45, 83].

Kuraridin, sophora flavanone G, kurarinone, kushenol F, and norkurarinol have extremely strong tyrosinase inhibitory activity [45-49]. Kurarinol, kuraridinol, and trifolirhizin markedly inhibited (>50\%) melanin synthesis [48, 49].

The mechanism of action of KS-Fs and kurarinone involves inhibition of tumor necrosis alpha one (TNF $\alpha \mathrm{l})$ induced NF- $\kappa \mathrm{B}$ activation and enhance apoptosis $[45,50$, 51]. The apoptosis-inducing effect was enhanced in the presence of taxol. In H460 xenograft mice treated with kurarinone, downregulation of Bcl-2 and upregulation of caspase 8 and caspase 3 in tumors were observed [45]. KS-Fs and kurarinone induce apoptosis in tumors by acting on multiple cellular targets, including inhibition of NF- $\kappa \mathrm{B}$ activation and multiple receptor tyrosine kinase activities [45]. Kurarinone and kuraridin attenuate $\mathrm{NF}-\kappa \mathrm{B}$ activation by inhibition of $\mathrm{I} \kappa \mathrm{B} \alpha$ proteolysis and p65 nuclear translocation, as well as phosphorylation of extracellular signal-regulated kinase (ERK)1/2, c-Jun N-terminal kinase (JNK), and p38 mitogenactivated protein kinases $[45,51]$. Constitutive NF- $\kappa \mathrm{B}$ and RSK2 activities are important hallmarks of human cancers (including hematopoietic malignancies and solid tumors), so prenylated flavanones represent an attractive class of natural inhibitors of the ERK/RSK2 signaling pathway for cancer therapy [85] (Table 2).

Fifty-six flavonoids have been identified from KS-Fs. Twenty-one of the KS-Fs have been found to have antitumor activities. Studies have demonstrated that more potent antitumor activities are observed in KS-Fs instead of KS-As fractions. KS-Fs were more than 10 -fold more potent than KS-As in the cell proliferation assay. Further evaluation of the safety and efficacy of KS-Fs in clinical oncology settings is warranted. KS-Fs could be developed as botanical drugs for solid tumors, and kurarinone could be used as a marker compound. Additional structural modifications of KS-Fs compounds could also generate more potent drug candidates.

\section{Conclusions and Future Perspectives}

This paper summarized the antitumor efficacy and mechanism of action of kushen and its constituents in vitro and in vivo. Many Patents of kushen extracts have been applied in USA, China and other countries (Table 3 ). These results strengthen the hypothesis that kushen (or its components) alone or combination with chemotherapy agents could modulate various molecular pathways in tumors or be used to treat cancer. Studies described here and elsewhere highlight the use of flavonoids of kushen as novel chemoprevention agents for cancer intervention. It is expected that future studies with kushen will help to define various molecular mechanisms and targets for the inhibition and apoptosis of tumor cells. The number of multicenter, large sample, 
TABLe 3: Patents of kushen extracts.

\begin{tabular}{|c|c|}
\hline Patent & Patent number \\
\hline Extract of Sophora flavescens flavonoids and uses thereof & US20050226943 \\
\hline Prenylated flavonoid derivatives having anti-inflammatory properties and Sophora flavescens extracts & Korea1020000077932 \\
\hline Extract of Sophora flavescens flavonoids and uses thereof & US20050226943 \\
\hline Compositions comprising matrine and dictamnine for treating or preventing cancer and other diseases & US2004192579A1 \\
\hline Medicine preparation containing matrine or epimatrine and its application in analgesic medicines & CN1347694A \\
\hline Use of oxidized matrine in preparation of chemicals for treating venereal diseases & CN1530108A \\
\hline A process for the manufacture of a herbal composition comprising a matrine & WO02067955A3 \\
\hline Use of oxidized matrine in preparation of chemicals for treating viral myocarditis & CN1530109A \\
\hline Double salt formed by inosine and matrine or oxymatrine and application thereof in field of medications & CN101724002A \\
\hline $\begin{array}{l}\text { Pharmaceutical purpose of compound comprising ferulic acid and matrine alkaloid in prevention and } \\
\text { treatment of osteoarthropathy }\end{array}$ & CN101669946A \\
\hline Application of oxidized matrine in preparing medicine for treatment of hepatitis B & CN1157717A \\
\hline Joint synergy of ferulic acid and matrine alkaloid and medical application thereof & CN101669945A \\
\hline Medicinal use of matrine alkaloid for promoting digestive tract power & CN1850075A \\
\hline Medicine composition containing silymarin and kurarinone or matrine and use thereof & CN101357129A \\
\hline $\begin{array}{l}\text { Pharmaceutical composition comprising kurarinone, magnolia vine fruit, and ginseng for treating } \\
\text { hepatitis }\end{array}$ & CN1970001A \\
\hline Use of kurarinone in preparation of medicine for postoperative intestine functional restoration & CN1923198A \\
\hline Combination of medication of containing kurarinone and glycyrrhetic acid, and application & CN1695624A \\
\hline Oxymatrine compositions and related methods for treating and preventing chronic infectious diseases & US2010022575A1 \\
\hline Pharmaceutical composition comprising oxymatrine and baicalin & CN1919205A \\
\hline Medicinal composition of oxymatrine and polysaccharide & CN101081240A \\
\hline Complex salt of silybin and oxymatrine or matrine and uses thereof & CN101157689A \\
\hline Double salt formed by inosine and matrine or oxymatrine and application thereof in field of medications & CN101724002A \\
\hline Method for separating matrine and oxymatrine from total matrines & CN101585837A \\
\hline Application of oxymatrine in preparing medicine for treating acute chronic cardiac insufficiency disease & CN101185647A \\
\hline Application of oxymatrine in preparing medicine to treat viral hepatitis $\mathrm{C}$ & CN1350848A \\
\hline Application of oxymatrine in preparing medicine to treat liver fibrosis & CN1350849A \\
\hline $\begin{array}{l}\text { Use of alkaloids extracted from Sophora flavescens in preparing medicine for treating diseases reduced by } \\
\text { mycoplasma, chlamydia and fungus }\end{array}$ & CN101336958A \\
\hline Compositions for improving skin conditions comprising matrine or its oxidized derivatives & US2010099698A1 \\
\hline Oxymatrine compositions and use thereof for treating and preventing chronic infectious diseases & WO2010011975A1 \\
\hline Preparation and use of silybin bis bias succinate oxymatrine double salt and matrine double salt & CN101297802A \\
\hline $\begin{array}{l}\text { Medication with spermicidal effect in vitro and bacteriostatic action and preparation method and } \\
\text { application thereof }\end{array}$ & CN101757140A \\
\hline Chinese medicine for hepatitis B and its preparation & CN1244409A \\
\hline Medicinal composition for preventing tumors & CN101073611A \\
\hline Application of kushen (Sophora flavescens) flavone in preparing antihypoglycemic agents & CN1348762A \\
\hline
\end{tabular}

randomized, double-blind, controlled chemoprevention clinical trials with kushen are very limited. Extensive clinical research is warranted to evaluate further the safety and chemoprevention efficacy of kushen alone or in combination with chemotherapy agents.

\section{Acknowledgments}

This work was supported by the National Natural Science Foundation (Grant no. 30701070), Scientific and Technological Project of Shanghai (11DZ1971702), Wang Bao-En
Hepatic Fibrosis Research Fund (20100048), Shanghai Rising-Star Program (08QA1406200), Xinglin Scholars Program of Shanghai University of Traditional Chinese Medicine, E-institute of Shanghai Municipal Education Commission (Project E03008), Innovative Research Team in Universities, Shanghai Municipal Education Commission, Shanghai Key Laboratory of Traditional Chinese Clinical Medicine, and Key Disciplines of Liver and Gall Bladder Diseases of State Administration of Traditional Chinese Medicine of the People's Republic of China. 


\section{References}

[1] "Sophora flavescens," in Shen Nong Ben Cao Jing, F. G. Sun and X. Y. Sun, Eds., p. 59, Scientific and Technical Documents Publishing House, 1st edition, 1999.

[2] "Sophora flavescens," in Zhonghua Bencao, vol. 4, pp. 634-643, Shanghai Science and Technology Press, 1st edition, 1999.

[3] Y. Wang, "Research progress on chemical constituents, preparative separation and quality of Sophora flavescens," Chinese Traditional Patent Medicine, vol. 19, pp. 39-41, 1997.

[4] M. Sun, J. Han, J. Duan et al., "Novel antitumor activities of Kushen flavonoids in vitro and in vivo," Phytotherapy Research, vol. 21, no. 3, pp. 269-277, 2007.

[5] H. Cheng, B. Xia, L. Zhang et al., "Matrine improves 2,4,6-trinitrobenzene sulfonic acid-induced colitis in mice," Pharmacological Research, vol. 53, no. 3, pp. 202-208, 2006.

[6] M. J. Zhang and J. Huang, "Recent research progress of antitumor mechnism matrine," China Journal of Chinese Materia Medica, vol. 29, no. 2, pp. 117-118, 2004.

[7] G. L. Xu, L. Yao, S. Y. Rao, Z. N. Gong, S. Q. Zhang, and S. Q. $\mathrm{Yu}$, "Attenuation of acute lung injury in mice by oxymatrine is associated with inhibition of phosphorylated p38 mitogenactivated protein kinase," Journal of Ethnopharmacology, vol. 98, no. 1-2, pp. 177-183, 2005.

[8] Z. Qin, H. Den, and H. Zhuang, "Effect of oxymatrine on prolonging the survival time of cardiac tissue allograft in mice and its immunologic mechanisms," Chinese Journal of Integrated Traditional and Western Medicine, vol. 10, no. 2, pp. 99-100, 1990.

[9] H. L. Cui, Y. F. Wang, X. L. Li, and Q. X. Kang, "Clinical observation of matrine injection in the treatment of 51 cases of various types of cancers," Shanxi Medical Journal, vol. 22, pp. 232-233, 1993.

[10] H. Bai, "Clinical observation of matrine injection in the treatment of middle and late stage cancers," Shenzhen Medical Journal, vol. 9, pp. 33-34, 1996.

[11] S. Huang, J. Li, J. L. Zhu, and X. L. Hu, "Clinical observation on the efficacy of matrine injection in treating middle and late stage gastric cancer," Chinese Journal of Integrated Traditional and Western Medicine, vol. 17, article 364, 1997.

[12] Z. J. Mei, Y. K. Hong, S. B. Zhao et al., "Clinical investigation of matrine Injection in treating late stage cancers," Huaxi Medical Journal, vol. 8, article 334, 1993.

[13] J. L. Zhu and J. Z. Chen, "Short-term observation on the efficacy of matrine injection in treating 79 cases of late stage cancers," Shandong Medical Journal, vol. 43, article 40, 2003.

[14] Z. J. Zhang, "Effects of matrine Injection in treating 44 cases of primary carcinoma of the liver," Guangxi Traditional Medicine, vol. 21, pp. 19-20, 1998.

[15] L. Q. Bao, A. M. Peng, and H. Y. Yuan, "Clinic study on the role of hydroxycamptothecin and mateling postoperative arterial infusion in the prevention of recurrence after curative resection for human hepatocellular carcinoma," Research on Prevention and Treament of Tumor, vol. 28, pp. 303-305, 2001.

[16] Y. J. Zhu, X. F. Chen, and Y. L. Huang, "Clinical observation on the efficacy of mateling injection combined with abdominal chemotherapy in treating 21 cases of malignant ascites," Chinese Journal of Integrated Traditional and Western Medicine on Gastro-Spleen, vol. 8, pp. 311-312, 2000.

[17] Y. F. Zhou, "Clinical observation on the efficacy of mateling injection combined with abdominal chemotherapy in treating malignant ascites," Journal of Emergency in Traditional Chinese Medicine, vol. 13, pp. 286-287, 2004.
[18] L. H. Shi and Y. H. Qiu, "Clinical investigation of kosam combined with chemotherapy to treat advanced malignant tumor," Journal of Tumor, vol. 7, pp. 95-97, 2001.

[19] Y. Z. Chen, Y. Q. Li, and Wang, "Fufang Kushen Injection in treatment of mild or moderate cancer pain," Journal of Beijing University of Traditional Chinese Medicine, vol. 35, pp. 61-69, 2012.

[20] L. H. Dou and Z. Guo, "Efficacy observation of fentanyl skin patches combined with compound Sophora flavescens injection in the treatment of cancer pain," China Pharmacy, vol. 23, pp. 1480-1482, 2012.

[21] C. J. Yuan, W. Z. Zhao, and J. K. Wang, "Efficacy observation of chemotherapy with compound Sophora flavescens injection in the treatment of elderly patients with advanced gastric cancer," Shandong Medicine, vol. 52, pp. 51-52, 2012.

[22] B. Feng and X. Q. Zhao, "Effect of composite Radix Sophora Flavescentis injection on immunological function in patients with lung cancer," China Pharmacy, vol. 18, pp. 2612-2613, 2007.

[23] X. H. Wang, Y. H. Li, J. Q. Yang, R. J. Zhang, J. G. Wang, and W. N. Hu, "Impact of compound matrine injection on clinical efficacy and immune functions among breast carcinoma patients undergoing postoperative chemotherapy," Chinese General Practice, vol. 14, pp. 2696-2698, 2011.

[24] Y. L. Wang, H. Fang, X. C. Wang, and K. M. Zhou, "To observe the clinical effect of complex kushen injection with TACE on middle and advanced stages of primary hepatic carcinoma," Shangdong Medicine, vol. 51, pp. 88-89, 2011.

[25] Q. Shi, Z. X. Wang, and Q. H. Zhao, "Compound matrine injection combined with FOLFIRI chemotherapy in the treatment of 50 patients with advanced colorectal cancer," Chinese Journal of New Drugs, vol. 19, pp. 1589-1592, 2010.

[26] Z. Lu, L. Qi, G. X. Li, C. G. Ma, J. Liu, and K. Liu, "Clinical efficiency of compound Kushen injection combined with radiotherapy in the treatment of patients with cervical cancer," China Journal of Hospital Pharmacy, vol. 31, pp. 1114-1117, 2011.

[27] H. J. Li, Y. G. Liang, and G. X. Zhang, "Effect of compound Sophora flavescens injection on attenuating the toxicity of chemotherapy for acute leukemia," China Pharmacy, vol. 23, pp. 323-325, 2012.

[28] L. Zhang, "Compound matrine injection in the treatment of 32 patients with malignant pleural effusion," Journal of Traditional Chinese Medicine, vol. 52, pp. 1149-1150, 2011.

[29] X. D. Guo, T. H. Jiang, W. W. Zhang, X. M. Zhang, and K. Q. Han, "Clinical observation on kurorinone in preventing hepatic injury caused by chemotherapy," Chinese Pharmaceutical Association, vol. 26, pp. 336-338, 2010.

[30] H. B. Tan, J. Zhang, and J. W. Zhang, "Tretment of advanced gastric cancer with composed Kushen injection combined with FOLFOX4 adjuvant chemotherapy," Medical Journal of Wuhan University, vol. 33, pp. 215-218, 2012.

[31] Z. F. Huang, J. B. Liu, H. Z. Li, and C. J. Huang, "Effect of combination of composite Sophorae injection and chemotherapy for treatment of 30 advanced gastric cancer patients," West China Medical Journal, vol. 24, pp. 2883-2885, 2009.

[32] Z. Y. Wang, G. S. Li, and H. X. Huang, "Clinical observation on treatment of 75 mid-late stage cancer patients with yanshu injection," Zhongguo Zhong Xi Yi Jie He Za Zhi, vol. 26, no. 8, pp. 681-684, 2006.

[33] M. J. Hu, H. Zeng, Y. L. Wu et al., "Synergistic effects of matrine and 5-fluorouracil on tumor growth of the implanted gastric cancer in nude mice," Chinese Journal of Digestive Diseases, vol. 6, no. 2, pp. 68-71, 2005. 
[34] S. Zhang, J. Qi, L. Sun et al., "Matrine induces programmed cell death and regulates expression of relevant genes based on PCR array analysis in C6 glioma cells," Molecular Biology Reports, vol. 36, no. 4, pp. 791-799, 2009.

[35] X. S. Liu and J. Jiang, "Molecular mechanism of matrineinduced apoptosis in leukemia K562 cells," American Journal of Chinese Medicine, vol. 34, no. 6, pp. 1095-1103, 2006.

[36] P. Yu, Q. Liu, K. Liu, K. Yagasaki, E. Wu, and G. Zhang, "Matrine suppresses breast cancer cell proliferation and invasion via VEGF-Akt-NF- $\kappa$ B signaling," Cytotechnology, vol. 59, no. 3, pp. 219-229, 2009.

[37] Y. Zhang, H. Zhang, P. Yu et al., "Effects of matrine against the growth of human lung cancer and hepatoma cells as well as lung cancer cell migration," Cytotechnology, vol. 59, no. 3, pp. 191-200, 2009.

[38] C. Luo, Y. Zhu, T. Jiang et al., "Matrine induced gastric cancer MKN45 cells apoptosis via increasing pro-apoptotic molecules of Bcl-2 family," Toxicology, vol. 229, no. 3, pp. 245-252, 2007.

[39] J. Q. Zhang, Y. M. Li, T. Liu et al., "Antitumor effect of matrine in human hepatoma G2 cells by inducing apoptosis and autophagy," World Journal of Gastroenterology, vol. 16, no. 34, pp. 4281-4290, 2010.

[40] C. H. Chui, F. Y. Lau, J. C. Tang et al., "Activities of fresh juice of Scutellaria barbata and warmed water extract of Radix Sophorae Tonkinensis on anti-proliferation and apoptosis of human cancer cell lines." International Journal of Molecular Medicine, vol. 16, no. 2, pp. 337-341, 2005.

[41] Y. Wang, C. Peng, G. Zhang, Y. Liu, H. Li, and J. Shan, "Study on invasion and metastasis related factors in differentiation of SMMC-7721 cells induced by matrine," Zhong Yao Cai, vol. 26, no. 8, pp. 566-569, 2003.

[42] X. Z. Wu, "A new classification system of anticancer drugsbased on cell biological mechanisms," Medical Hypotheses, vol. 66, no. 5, pp. 883-887, 2006.

[43] X. Y. Liu, H. Fang, Z. G. Yang et al., "Matrine inhibits invasiveness and metastasis of human malignant melanoma cell line A375 in vitro," International Journal of Dermatology, vol. 47, no. 5, pp. 448-456, 2008.

[44] Z. J. Dai, J. Gao, X. J. Wang et al., "Apoptotic mechanism of gastric carcinoma cells induced by matrine injection," Zhonghua Wei Chang Wai Ke Za Zhi, vol. 11, no. 3, pp. 261265,2008 .

[45] J. Han, M. Sun, Y. Cui et al., "Kushen flavonoids induce apoptosis in tumor cells by inhibition of NF- $\kappa$ B activation and multiple receptor tyrosine kinase activities," Phytotherapy Research, vol. 21, no. 3, pp. 262-268, 2007.

[46] M. Y. Sun, J. Zuo, J. F. Duan et al., "Antitumor activities of kushen flavonoids in vivo and in vitro," Zhong Xi Yi Jie He Xue Bao, vol. 6, no. 1, pp. 51-59, 2008.

[47] J. K. Son, J. S. Park, J. A. Kim, Y. Kim, S. R. Chung, and S. H. Lee, "Prenylated flavonoids from the roots of Sophora flavescens with tyrosinase inhibitory activity," Planta Medica, vol. 69, no. 6, pp. 559-561, 2003.

[48] S. J. Kim, K. H. Son, H. W. Chang, S. S. Kang, and H. P. Kim, "Tyrosinase inhibitory prenylated flavonoids from Sophora flavescens," Biological and Pharmaceutical Bulletin, vol. 26, no. 9, pp. 1348-1350, 2003.

[49] S. K. Hyun, W. H. Lee, D. M. Jeong, Y. Kim, and J. S. Choi, "Inhibitory effects of kurarinol, kuraridinol, and trifolirhizin from Sophora flavescens on tyrosinase and melanin synthesis," Biological and Pharmaceutical Bulletin, vol. 31, no. 1, pp. 154 $158,2008$.
[50] Y. B. Ryu, I. M. Westwood, N. S. Kang et al., "Kurarinol, tyrosinase inhibitor isolated from the root of Sophora flavescens," Phytomedicine, vol. 15, no. 8, pp. 612-618, 2008.

[51] W. vanden Berghe, A. de Naeyer, N. Dijsselbloem, J. P. David, D. de Keukeleire, and G. Haegeman, "Attenuation of ERK/RSK2-driven $\mathrm{NF} \kappa \mathrm{B}$ gene expression and cancer cell proliferation by kurarinone, a lavandulyl flavanone isolated from Sophora flavescens Ait. roots," Endocrine, Metabolic and Immune Disorders, vol. 11, no. 3, pp. 247-261, 2011.

[52] J. P. Lai, X. W. He, Y. Jiang, and F. Chen, "Preparative separation and determination of matrine from the Chinese medicinal plant Sophora flavescens Ait by molecularly imprinted solid-phase extraction," Analytical and Bioanalytical Chemistry, vol. 375, no. 2, pp. 264-269, 2003.

[53] L. P. Zhang, J. K. Jiang, J. W. O. Tam et al., "Effects of matrine on proliferation and differentiation in K-562 cells," Leukemia Research, vol. 25, no. 9, pp. 793-800, 2001.

[54] J. Y. Liu, J. H. Hu, Q. G. Zhu, F. Q. Li, J. Wang, and H. J. Sun, "Effect of matrine on the expression of substance $\mathrm{P}$ receptor and inflammatory cytokines production in human skin keratinocytes and fibroblasts," International Immunopharmacology, vol. 7, no. 6, pp. 816-823, 2007.

[55] L. Zhang, T. Wang, X. Wen et al., "Effect of matrine on HeLa cell adhesion and migration," European Journal of Pharmacology, vol. 563, no. 1-3, pp. 69-76, 2007.

[56] Y. Li, B. Wang, C. Zhou, and Y. Bi, "Matrine induces apoptosis in angiotensin II-stimulated hyperplasia of cardiac fibroblasts: effects on Bcl-2/Bax expression and caspase-3 activation," Basic and Clinical Pharmacology and Toxicology, vol. 101, no. 1, pp. 1-8, 2007.

[57] J. Zou, Z. H. Ran, Q. Xu, and S. D. Xiao, "Experimental study of the killing effects of oxymatrine on human colon cancer cell line SW1116," Chinese Journal of Digestive Diseases, vol. 6, no. 1, pp. 15-20, 2005.

[58] H. S. Mao, H. Y. Liu, and C. Li, "Modulation of the malignant phenotype and the immunological response of tumor cells by Sophora flavescens Ait (AF-7)," Chinese Journal of Clinical Oncology, vol. 23, no. 11, pp. 799-803, 1996.

[59] L. J. Li, Z. Q. Chen, Y. Y. Zheng, W. X. Tang, and Y. Yu, "In vitro effects of oxymatrine on human ovarian cancer cell SKOV-3," Journal of Practical Oncology, vol. 17, pp. 100-101, 2003.

[60] L. T. Ma, Y. Zhang, S. H. Wen, Y. J. He, G. F. Kang, and J. K. Jiang, "Experimental study of the antitumor effects of oxymatrine on murine $\mathrm{H} 22$ hepatoma," Academic Journal of Chongqing Medical University, vol. 30, pp. 178-182, 2005.

[61] Y. Wang, W. K. Si, P. Li, and J. Yao, "Effects of matrine and oxymatrine on the proliferation and apoptosis of A549 cells," Academic Journal of Third Military Medical University, vol. 26, pp. 778-780, 2004.

[62] Q. Z. Kong, T. Huang, D. S. Huang et al., "Inhibitory effects of oxymatrine on angiogenesis of murine S180 sarcoma," China Pharmacist, vol. 6, pp. 769-771, 2003.

[63] G. W. Xu, S. J. Man, Z. S. Wang, and L. B. Wang, "Effect of oxymatrine on immunology of tumor-bearing mice," Chinese Journal of Clinical Oncology and Rehabilitation, vol. 8, pp. 910, 2001.

[64] X. S. Liu, J. Jiang, X. Y. Jiao, Y. E. Wu, and J. H. Lin, "matrineinduced apoptosis in leukemia U937 cells: involvement of caspases activation and MAPK-independent pathways," Planta Medica, vol. 72, no. 6, pp. 501-506, 2006.

[65] X. Y. Liu, H. Fang, Z. G. Yang et al., "Matrine inhibits invasiveness and metastasis of human malignant melanoma cell 
line A375 in vitro," International Journal of Dermatology, vol. 47, no. 5, pp. 448-456, 2008.

[66] H. Jiang, C. Hou, S. Zhang et al., "Matrine upregulates the cell cycle protein E2F-1 and triggers apoptosis via the mitochondrial pathway in K562 cells," European Journal of Pharmacology, vol. 559, no. 2-3, pp. 98-108, 2007.

[67] S. Zhang, J. Qi, L. Sun et al., "Matrine induces programmed cell death and regulates expression of relevant genes based on PCR array analysis in C6 glioma cells," Molecular Biology Reports, vol. 36, no. 4, pp. 791-799, 2009.

[68] L. Yang, J. W. Chen, and Y. S. Lin, "Clinical observation on the efficacy of mateling injection combined with radiotherapy in treating nasopharyngeal tumors," Strait Pharmaceutical Journal, vol. 8, pp. 41-43, 1996.

[69] M. J. Hu, H. Zeng, Y. L. Wu et al., "Synergistic effects of matrine and 5-fluorouracil on tumor growth of the implanted gastric cancer in nude mice," Chinese Journal of Digestive Diseases, vol. 6, no. 2, pp. 68-71, 2005.

[70] C. Luo, Y. Zhu, T. Jiang et al., "Matrine induced gastric cancer MKN45 cells apoptosis via increasing pro-apoptotic molecules of Bcl-2 family," Toxicology, vol. 229, no. 3, pp. 245-252, 2007.

[71] L. Ma, S. Wen, Y. Zhan, Y. He, X. Liu, and J. Jiang, "Anticancer effects of the Chinese medicine matrine on murine hepatocellular carcinoma cells," Planta Medica, vol. 74, no. 3, pp. 245251, 2008.

[72] L. Zhang, T. Wang, X. Wen et al., "Effect of matrine on HeLa cell adhesion and migration," European Journal of Pharmacology, vol. 563, no. 1-3, pp. 69-76, 2007.

[73] M. Q. Song, J. S. Zhu, J. L. Chen et al., "Synergistic effect of oxymatrine and angiogenesis inhibitor NM-3 on modulating apoptosis in human gastric cancer cells," World Journal of Gastroenterology, vol. 13, no. 12, pp. 1788-1793, 2007.

[74] Q. Ling, X. Xu, X. Wei et al., "Oxymatrine induces human pancreatic cancer PANC-1 cells apoptosis via regulating expression of Bcl-2 and IAP families, and releasing of cytochrome c," Journal of Experimental and Clinical Cancer Research, vol. 30, no. 1, article 66, 2011.

[75] Y. Zhang, B. Piao, Y. Zhang et al., "Oxymatrine diminishes the side population and inhibits the expression of $\beta$-catenin in MCF-7 breast cancer cells," Medical Oncology, vol. 28, supplement 1, pp. 99-107, 2011.

[76] Y. G. Hong, T. Huang, and J. S. Wang, "Effect of Compound kushen injection combined with chemotherapy on immune function and CEA in advanced lung adenocarcinoma," Chinese Journal of New Drugs, vol. 21, no. 14, pp. 1633-1635, 2012.

[77] J. Chen, Q. Mei, Y. C. Xu, J. Du, Y. Wei, and Z. M. Xu, "Effects of matrine Injection on T-lymphocyte subsets of patients with malignant tumor after gamma knife radiosurgery," Zhong Xi Yi Jie He Xue Bao, vol. 4, no. 1, pp. 78-79, 2006.

[78] Z. J. Dai, J. Gao, W. Y. Wu et al., "Effect of matrine injections on invasion and metastasis of gastric carcinoma SGC-7901 cells in vitro," Zhong Yao Cai, vol. 30, no. 7, pp. 815-819, 2007.

[79] M. Kuroyanagi, T. Arakawa, Y. Hirayama, and T. Hayashi, "Antibacterial and antiandrogen flavonoids from Sophora flavescens," Journal of Natural Products, vol. 62, no. 12, pp. 1595-1599, 1999.

[80] E. R. Woo, J. H. Kwak, H. J. Kim, and H. Park, "A new prenylated flavonol from the roots of Sophora flavescens," Journal of Natural Products, vol. 61, no. 12, pp. 1552-1554, 1998.

[81] S. Y. Ryu, S. U. Choi, S. K. Kim, Z. No, C. O. Lee, and J. W. Ahn, "In vitro antitumour activity of flavonoids from Sophora flavescens," Phytotherapy Research, vol. 11, no. 1, pp. 51-53, 1997.
[82] T. H. Kang, S. J. Jeong, W. G. Ko et al., "Cytotoxic lavandulyl flavanones from Sophora flavescens," Journal of Natural Products, vol. 63, no. 5, pp. 680-681, 2000.

[83] Y. Y. Zhao and R. Y. Zhang, "Research on chemical constituents of Sophora flavescens," Natural Product Research And Development, vol. 3, pp. 93-103, 1991.

[84] P. Ding, D. Chen, K. F. Bastow, A. K. Nyarko, X. Wang, and K. H. Lee, "Cytotoxic isoprenylated flavonoids from the roots of Sophora flavescens," Helvetica Chimica Acta, vol. 87, no. 10, pp. 2574-2580, 2004.

[85] J. M. Han, Y. Y. Jin, H. Y. Kim, K. H. Park, W. S. Lee, and T. S. Jeong, "Lavandulyl flavonoids from Sophora flavescens suppress lipopolysaccharide-induced activation of nuclear factor- $\kappa \mathrm{B}$ and mitogen-activated protein kinases in RAW264.7 cells," Biological and Pharmaceutical Bulletin, vol. 33, no. 6, pp. 1019-1023, 2010. 


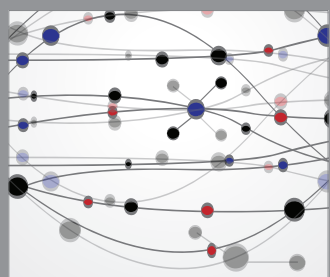

The Scientific World Journal
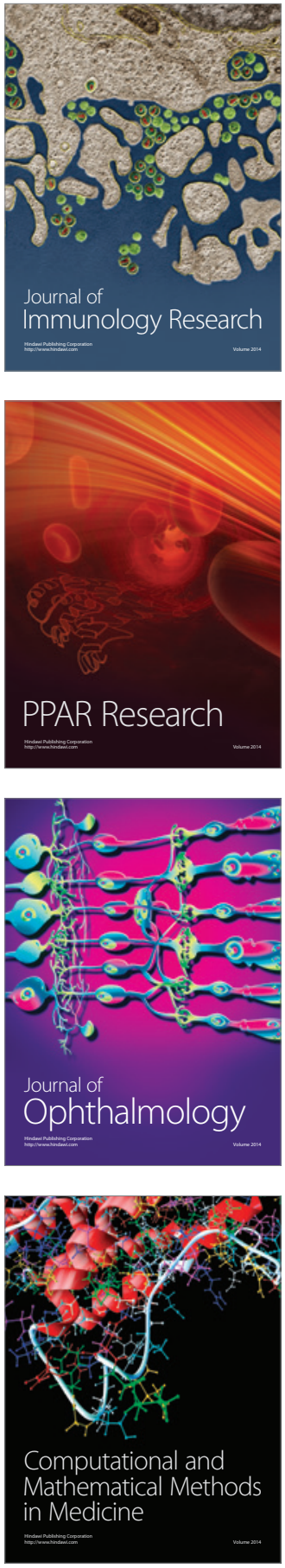

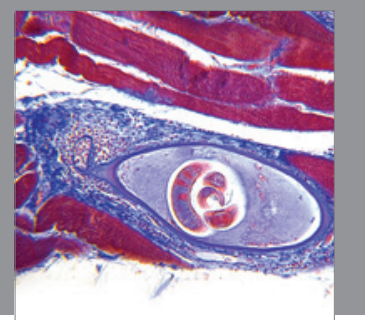

Gastroenterology

Research and Practice
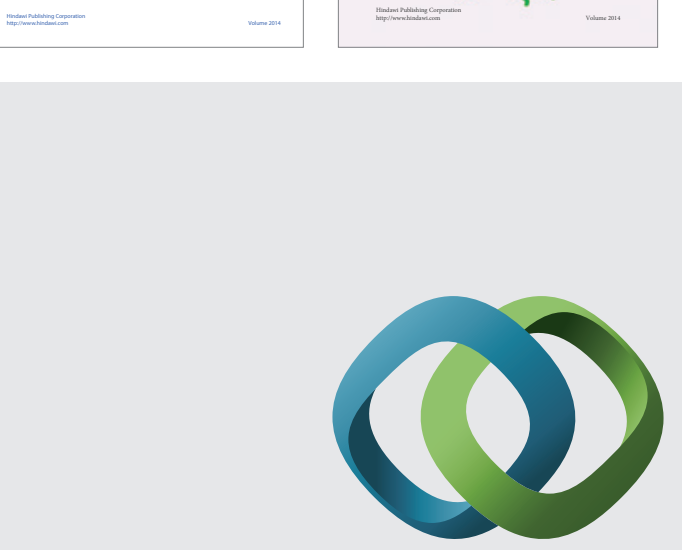

\section{Hindawi}

Submit your manuscripts at

http://www.hindawi.com
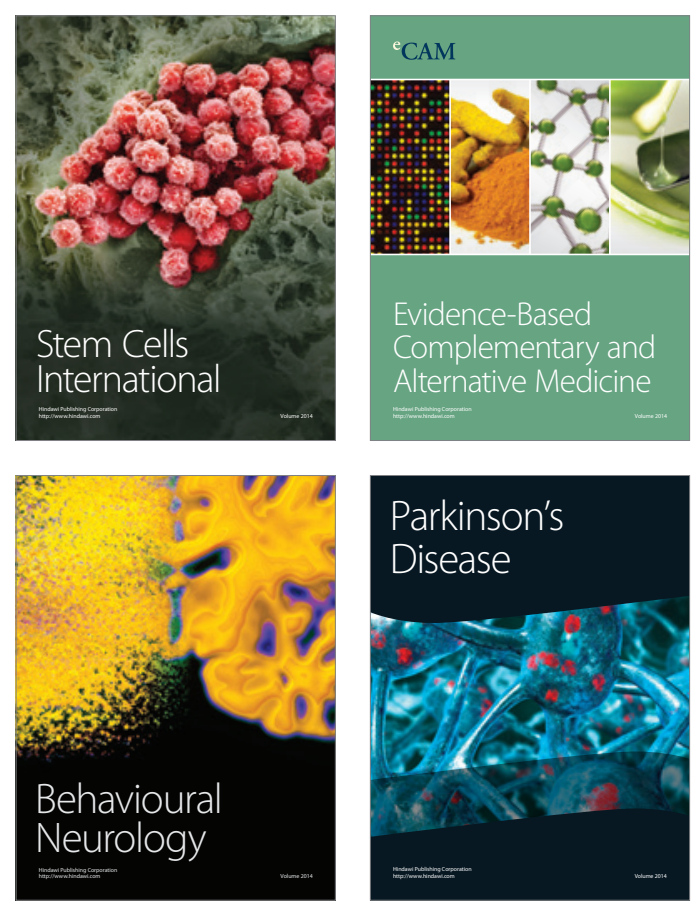

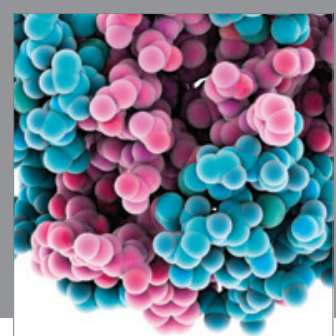

Journal of
Diabetes Research

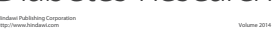

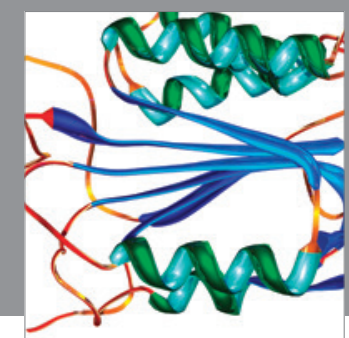

Disease Markers
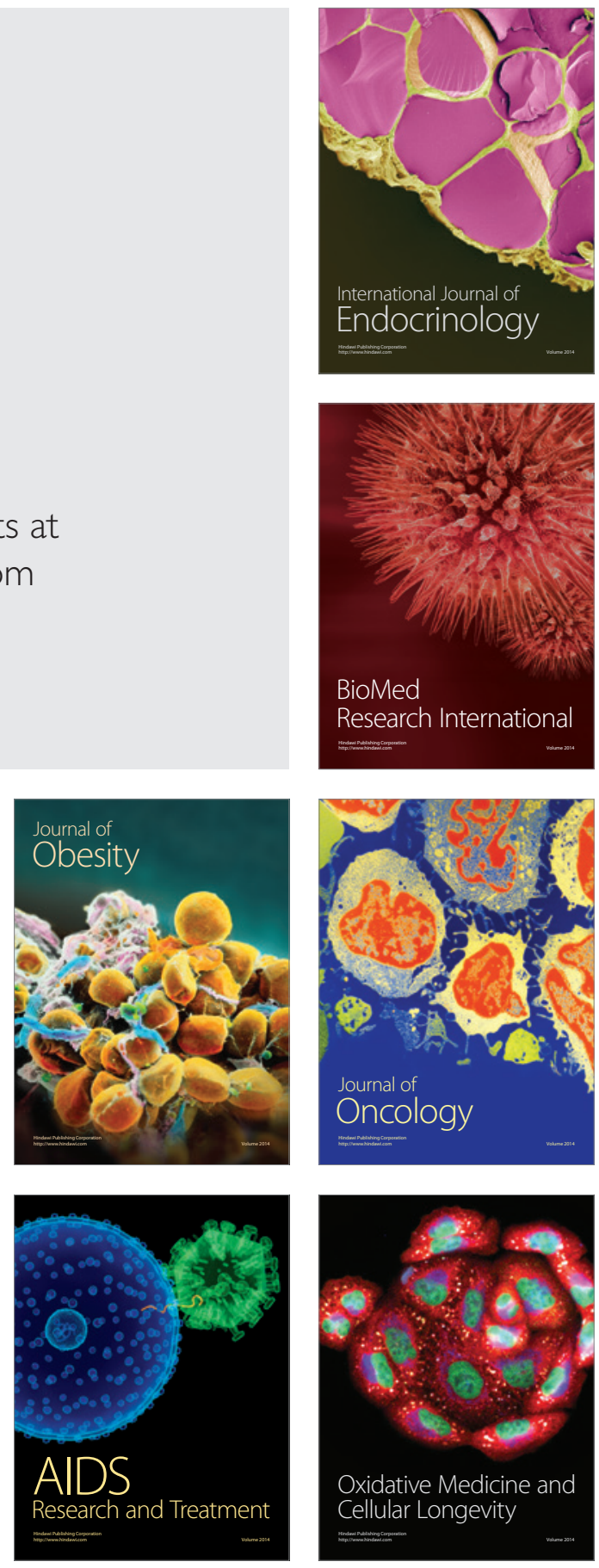